\title{
FRONÉSIO VS. SELÊNIO: A MERETRIX PLAUTINA
}

\author{
Caroline Barbosa Faria Ferreira*
}

Universidade Federal do Espírito Santo

\begin{abstract}
Resumo. Neste trabalho analisaremos duas das principais meretrizes do teatro plautino, Fronésio, da peça $O$ truculento, e Selênio, da peça Comédia da cestinha, a fim de observar como essa personagem é construída pelo autor. Para tanto, analisaremos o discurso das meretrizes e também as falas de outras personagens que se referem a elas. A análise será estruturada de acordo com o conceito de ethos discursivo, situado no âmbito da Análise do Discurso Francesa, desenvolvido por Dominique Maingueneau a partir da noção de ethos retórico.
\end{abstract}

Palavras-chave. Plauto, meretriz, ethos.

D.o.I. 10.11606/issn.2358-3150.v19i2p69-79

A PERSONAGEM DA MERETRIZ APARECE EM NúMERo BASTANTE EXPRESSIVO nas comédias de Plauto. George E. Duckworth $(1994,258)$ divide as meretrices plautinas em duas categorias: (1) aquelas que são inteligentes, experientes, mercenárias e sem sentimentos, dispostas a arruinarem os filhos de famílias abastadas e os velhos libidinosos para alcançarem seus objetivos. Preferem antes o dinheiro que o amor, pois o dinheiro é o fator determinante para que os seus favores sejam alcançados; (2) jovens apaixonadas, fiéis aos seus amantes, que normalmente não se entregam a outros homens por interesse.

Dentre as meretrices interesseiras, as principais representantes são Fronésio, de O Truculento, Erócio, de Menecmos e as irmãs Bacchis, de As duas báquides. Plauto descreve com frequência os subterfúgios que essas meretrizes utilizavam para obter presentes de seus amantes. Às vezes, através de reclamações, estas obtinham casas ou propriedades de jovens ingênuos.

No segundo grupo, temos as apaixonadas meretrizes Selênio, de $A$ comédia da cestinha, Filocomásio, de $O$ soldado fanfarrão, Filênio, de $A$ comédia dos asnos e Filemátio de $A$ comédia dos fantasmas como principais representantes. Essas personagens normalmente sofrem durante toda a peça grande oposição do leno ou da lena para poder concretizar o seu amor.

\footnotetext{
Mestre em Letras (Literaturas Clássicas) pela Universidade Federal do Espírito Santo (2013).

"Artigo recebido em 05.set.2016 e aceito para publicação em 25.out.2016.
} 
Acerca dessa diferenciação no caráter da meretrix plautina, Anne Duncan ${ }^{1}$ afirma que a boa e sincera meretrix é uma pseudo-hetaira, uma menina que, apesar de ocupar a posição de meretriz momentaneamente, ao fim da peça descobre ser uma cidadã, e se casa com o jovem por quem está apaixonada. Segundo a autora, a verdadeira meretrix plautina, que é semelhante à hetaira na comédia nova grega, é aquela que tem um mau caráter. Sobre as primeiras, Duckworth $(1994,259)$ afirma que as prostitutas que são apaixonadas por algum jovem são muito mais simpáticas e compreensivas, embora Plauto enfatize em suas peças muito mais o humor e a inteligência do que as boas ações dessas personagens. O termo meretrix, para o autor, é talvez mal justificado, já que as jovens estão vivendo com o homem de sua escolha. Meninas como Selênio, Filênio e Filemátio, expressam o seu amor e lealdade por um homem e resistem aos conselhos de mulheres mais experientes que dizem que elas devem estar preocupadas apenas com o dinheiro e não devem se apaixonar por ninguém. ${ }^{2}$

Considerando a grande ocorrência dessas personagens nas peças de Plauto, nos ateremos neste artigo apenas àquelas que têm um maior destaque nas peças do autor, a fim de observarmos quais os recursos utilizados para a construção do ethos da meretrix plautina. São elas: Fronésio, de O Truculento, como representação da meretriz interesseira e Selênio, de A comédia da cestinha, representando a meretriz apaixonada.

\section{A CONSTRUÇÃO DA PERSONAGEM FRONÉSIO NA PEÇA O TRUCULENTO}

Sobre a peça $O$ Truculento, Ritschl ${ }^{3}$ afirma que, à primeira vista, a comédia parece a menos feliz das peças plautinas, pela escassa intriga e por ser aparentemente pouco motivado o conflito entre os três amantes. Mas existe um centro na ação: Fronésio, que com a arte de atrair a si as suas vítimas, consegue enganar os seus três amantes ao longo de toda a peça.

Duncan afirma que a meretriz habilmente chamada de Fronésio, sem dúvida, é a pior das más meretrizes do corpus plautino. Ela é o servus callidus da peça $O$ Truculento. Fronésio prova ser uma mestra de inteligentes estratagemas com os quais engana três amantes, jogando um contra o outro para despojá-los de seus bens. ${ }^{4}$

\footnotetext{
${ }^{1}$ Duncan, in Faraone e Mcclure 1930, 257.

2 Sobre esta questão cf. Pl. Cist. 78-88; As. 537-42; Mos. 214ss.

${ }^{3}$ Ritschl apud Perna 1954, 443.

${ }^{4}$ Cf. Duncan, in Faraone e Macclure 1930, 264.
} 
Já no prólogo da peça, Fronésio nos é apresentada de forma negativa, como uma mulher interesseira, que tem muita facilidade em arruinar os seus amantes. A personagem que profere o prólogo, assim diz ao público:

\author{
hic habitat mulier, nomen cui est Phronesium; \\ haec huius saecli mores in se possidet: \\ numquam ab amatore [suo] postulat id quod datumst, \\ sed relicuom dat operam ne sit relicuom, \\ poscendo atque auferendo, ut mos est mulierum; \\ nam omnes id faciunt, cum se amari intellegunt. ${ }^{5}$ (v.12-17)
}

Aqui mora uma mulher chamada Fronésio. Ela possui em si os costumes deste nosso tempo: nunca reclama aos [seus] amantes o que estes já lhe deram, mas, quanto ao que lhes resta, esforça-se por que nada lhes reste, pedindo e arrebanhando, como é costume das mulheres. Na verdade todas procedem assim, quando sentem que são amadas. ${ }^{6}$

Os traços apontados no Prólogo evidenciam a natureza má da meretriz. Seu ethos é construído a partir da primeira fala da peça e é corroborado pelas falas das personagens e também pelas ações da meretriz.

A peça é iniciada com a seguinte fala do adulescens Diniarco, um dos três amantes de Fronésio:

non omnis aetas ad perdiscendum sat est amanti, dum id perdiscat, quot pereat modis; neque eam rationem eapse umquam educet Uenus, quam penes amantum summa summarum redit, quot amans exemplis ludificetur, quot modis pereat quotque exoretur exorabulis: quot illic blanditiae, quot illic iracundiae sunt, quot tsui perclamandat, di uostram fidem, hui! quid peiierandum est etiam, praeter munera: primumdum merces annua, is primus bolust, ob eam-tres noctes dantur; interea loci aut aera aut uinum /aut oleum/ aut triticum; temptat benignusne an bonae frugi sies: quasi in piscinam rete qui iaculum parat, quando abiit rete pessum, adducit lineam; si iniecit rete, piscis, ne ecfugiat cauet: dum huc dum illuc rete tort, impedit piscis usque adeo donicum eduxit foras. itidem est, amator sei quod oratur dedit atque est benignus potius quam frugi bonae. adduntur noctes, interim ille hamum uorat, si semel amoris poculum accepit meri

\footnotetext{
${ }^{5}$ O texto latino utilizado no artigo é o estabelecido por Lindsay 1989.
}

${ }^{6}$ As traduções da peça $O$ Truculento são de Adriano Milho Cordeiro. 
eaque intra pectus se penetrauit potio, extemplo et ipsus periit et res et fides. si iratum scortum fortest amatori suo, bis perit amator, ab re(d) atque animo simul; sin alter alteri propitiust, tidemt perit: si raras noctes ducit, $\mathrm{ab}$ animo perit; si /increbrauit. ipsus gaudet, res perit. 50 [intercepta in aedibus lenonis] $50 \mathrm{a}$ priu' quam unum dederis, centum quae poscat parat: aut periit aurum aut conscissa pallula est aut empta ancilla aut aliquod uasum argenteum aut uasum ahenum taliquod aut lectus laptilest aut armariola Graeca, aut-aliquid semper <est> quod tpetrat debeatque amans scorto suo. atque haec celamus nos clam magna industria, quom rem fidemque nosque nosmet perdimus, ne qui parentes neu cognati sentiant; quos cum celamus si faximus conscios, qui nostrae aetati tempestiuo temperent, unde anteparta demus postpartoribus, faxim lenonum nec scortorum plus siet et minu' damnosorum hominum quam nunc sunt siet. nam nunc lenonum et scortorum plus est fere, quam olim muscarum est quom caletur maxume. nam nusquam alibi si sunt, circum argentarias tscortit lenones qui adsident cottidie, ea nimia est ratio; quippe qui certo scio, fere plus scortorum esse iam quam ponderum. (v. 22-69)

Uma vida inteira não é suficiente para um amante aprender satisfatoriamente, se é que o aprende, de quantos modos pode arruinar-se. E nunca a própria Vênus, sob cujo poder estão os mais importantes assuntos dos amantes, fará essa conta: de quantas formas o amante pode ser enganado, de quantos modos pode ser arruinado, com quantas súplicas pode ser amaciado. Quantas lisonjas aí há, quantas birras aí há! Quanta sobranceria! Ó deuses, a vossa bondade, ai! Quanto tem que se perder, já sem contar com as prendas. Em primeiro lugar, o sustento de um ano: esse é o primeiro golpe. Em troca dele, concedem-se três noites ao amante. De permeio, fala-se ou num altar, ou em vinho, ou em azeite, ou em trigo. Está a sondar se és generoso ou agarrado aos teus bens. Tal como o pescador que lança a rede para o viveiro — logo que a rede vai ao fundo, puxa a linha e, se o peixe tiver entrado na rede, trata de não o deixar escapar, cercando o peixe com a rede por todos os lados até o tirar para fora, assim sucede com o amante. Se ele dá o que lhe é pedido e é mais generoso do que agarrado aos seus bens, concedem-se-lhe mais algumas noites; durante esse tempo ele morde o isco.

Mal ele experimentou uma taça de amor puro e essa bebida penetrou até as suas entranhas, imediatamente se arruinou a si próprio, aos seus bens e à sua reputação. Se acaso uma prostituta se irrita com o amante, o amante arruína-se duplamente: nos seus bens e ao mesmo tempo no coração. Se, pelo contrário, 
um se entrega ao outro, também fica arruinado: se obtém poucas noites, sofre no seu coração; se se torna mais assíduo, sente-se feliz por si próprio, mas os bens arruínam-se. É assim nas casas de lenocínio. Ainda lhe não deste um único presente, ela já está a pedir-te um cento: ou foi uma joia de ouro que desapareceu, ou uma mantilha que se rasgou, ou comprou uma serva ou algum vaso de prata, ou um vaso de bronze, ou algum leito de pedra, ou uns pequenos armários gregos ou $\ldots<$ há $>$ sempre qualquer coisa, de pedra que o amante deve à sua amante. E, enquanto arruinamos os nossos bens, a nossa reputação e a nós próprios, nós ocultamos isso, em segredo, com o maior cuidado, não venham os nossos pais e os nossos familiares a sabê-lo. Se, em vez de nos escondermos, nos confiássemos a eles, para que a tempo refreassem a nossa juventude, a fim de não entregarmos a herdeiros futuros os bens herdados dos nossos antepassados, eu suponho que haveria <aqui muito menos> chulos e prostitutas e menos homens gastadores do que existem presentemente.

De facto, hoje em dia há quase mais chulos e prostitutas do que moscas em plena canícula. Com efeito, como se não houvesse outro lugar, o número de prostitutas <e > chulos que acampam todos os dias em volta das mesas dos banqueiros é incalculável. Pois estou seguro de que há lá, agora, mais prostitutas do que pesos de balanças.

É interessante destacar que Diniarco, o amante arruinado, não inicia a peça falando sobre Fronésio, causa de sua ruína, mas constrói uma imagem das meretrizes de um modo geral, classificando-as como mulheres que estão dispostas a tudo para conseguirem riqueza e poder e que não demonstram nenhuma consideração por seus amantes. Para tornar mais evidente essa natureza maléfica, Diniarco compara as meretrizes ao pescador, que lança suas redes ao mar para pescar muitos peixes, e os cerca por todos os lados até que eles estejam completamente vencidos. Mais à frente, após falar sobre as meretrizes de um modo geral, quando o cenário que ele necessita para reforçar as suas afirmações já está preparado, Diniarco fala sobre a meretriz Fronésio:

nam mihi haec meretrix quae hic habet, Phronesium, suom nomen omne ex pectore exmouit meo,

[Phronesim, nam phronesis est sapientia].

nam me fuisse huic fateor summum atque intumum, quod amantis multo pessumum est pecuniae. (v. 76-80)

Esta meretriz que tem Fronésio como nome próprio, expulsou do meu espírito, por completo, a querida Sabedoria. É que phronesis em grego significa sabedoria. Eu confesso que fui o seu amante favorito e íntimo, o que é muitíssimo mal para a fortuna de um amante;

E ao público ainda diz:

quasi uolturii triduo

priu' praediuinant, quo die essuri sient:

illum inhiant omnes, illi est animus omnibus (...) (v.337-9) 
Tal como abutres que pressentem três dias antes o momento em que vão comer, todas elas estão esfomeadas por ele (Astrabax), o pensamento de todas está nele $(\ldots)$

Podemos também perceber nas comédias plautinas que os escravos quase sempre têm uma relação hostil com as meretrizes interesseiras. Eles normalmente se referem a elas como pessoas que não tem nenhum escrúpulo. O escravo de Diniarco, assim fala sobre essas mulheres:

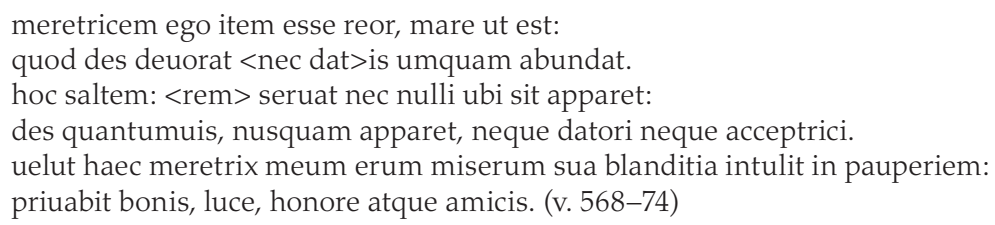

Eu sou da opinião que uma meretriz é tal qual o mar. Devora o que lhe deres e nunca transborda de presentes. Mas o mar ao menos guarda o que recebeu. + Comigo guarda-se t, aparece. Desde quanto deres a uma meretriz, em parte nenhuma aparece, nem para o que dá nem para a que recebe. Vejam como, por exemplo, com as suas caricias, esta meretriz levou a penúria o meu desgraçado amo: privou-o dos seus bens, da vida, da honra e dos amigos.

É interessante notar que, somente depois de já construída textualmente através das demais personagens da peça, Fronésio, personagem principal, entra em cena (última cena do ato I), para confirmar aquilo que as demais personagens haviam falado sobre ela. Seu estilo verbal e suas ações confirmam a identidade que havia sido construída anteriormente pelas demais personagens na peça. Fazendo referência ao seu próprio caráter, ela fala ao público sobre a mentira que diria ao soldado a fim de conseguir enganá-lo:

edepol commentum male, quomque eam rem in corde agito, nimio - minu' perhibemur malae quam sumus ingenio. (v.451-2)

Por Pólux, que invenção mais torpe! E quando eu perscruto o meu coração sobre este assunto, somos tidas muito menos malvadas do que somos por natureza!

E ainda:

propter hunc spes etiamst hodie tactuiri militem;

quem ego ecastor mage amo quam me, dum-id quod cupio inde aufero. quae quom multum abstulimus, hau multum <eius $>$ apparet quod datum est: ita sunt gloriae meretricum. (v. 885-8)

Graças a ele (Diniarco), tenho esperança de que ainda hoje irá ser enganado o soldado que, por Castor, eu amo mais do que a mim própria enquanto puder 
tirar dele aquilo que desejo! Embora tiremos muito, muito daquilo que nos foi dado nunca aparece! É esta a reputação das meretrizes!

E mais a frente acrescenta para si mesma: "Por Castor, que eu hoje hei de destruir este homem com os meus astutos estratagemas!" (v. 892).

É comum que esse tipo de meretriz, cúpida por definição, nunca esteja satisfeita com os presentes dos seus amantes. A Estratófanes, Fronésio diz, demonstrando sua insatisfação frente a um reconhecimento tão "pequeno" aos seus favores: "Ser-me dado um presente tão pequenino em paga de tão grandes trabalhos?!" (v. 537).

A comédia termina com uma fala representativa da meretriz ao seu público, que mais uma vez reforça a imagem desta personagem que foi construída ao longo da peça através do seu discurso e de outras personagens e também através de suas ações:

lepide ecastor aucupaui atque ex mea sententia, meamque ut rem uideo bene gestam, uostram rusum bene geram: tromabot si quis animatust facere, faciat ut sciam. ueneris causa adplaudite: eius haec in tutelast fabula. spectatores, bene ualete, plaudite atque exsurgite. (v. 964-8)

Por Castor, que linda caçada eu fiz cacei lindamente e conforme ao meu desejo! E como estou a ver o meu negócio bem gerido, em seguida vou gerir o vosso. Por favor, se alguém está decidido a fazer negócio, faça-me chegar uma proposta! Em honra de Vênus, venham os aplausos: esta comédia está sob a sua tutela! (...)

\section{A CONSTRUÇÃO DA PERSONAGEM SELÊNIO NA PEÇA A COMÉDIA DA CESTINHA}

Selênio é uma meretriz diferente de Fronésio e de outras meretrizes interesseiras presentes nas peças plautinas. Por ter se apaixonado pelo jovem Alcesimarco, a meretriz sofre durante toda a peça. Gimnásio assim descreve a amiga:

numquam ego te tristorem uidi esse. quid, cedo, te opsecro, tam abhorret hilaritudo? neque munda adaeques es, ut soles (hoc sis uide, ut petiuit suspiritum alte) et pallida es (v.53-62).

Eu nunca te vi tão triste. Diz-me, por favor, por que está a tua alegria a desaparecer tanto? E também não está tão elegante como de costume - olha, vê só que suspiro tão profundo ela soltou - e está pálida. ${ }^{?}$

${ }^{7}$ As traduções da peça A comédia da cestinha são minhas. 
Questionada por Gimnásio sobre o motivo de seu comportamento, Selênio responde: "at mihi cordolium est". (v.62) (É que o meu coração está doendo). Gimnásio então diz:

quid? id unde est tibi cor? commemora obsecro; quod neque ego habeo neque quisquam alia mulier, ut perhibent uiri. (v.63-4)

O que? De onde é este teu coração? Diga-me, eu te peço. Porque nem eu tenho, nem qualquer outra mulher, assim falam os homens.

\section{E Selênio responde:}

si quid est quod doleat, dolet; si autem non est-tamen hoc hic dolet. (v. 65)

Se tem algo que possa doer, dói, se, por outro lado, não existe, mesmo assim, isto está aqui a doer-me.

Na primeira cena da peça, a lena, mãe de Gimnásio, explica a Selênio o motivo pelo qual ela e Melênis, mãe da jovem, se tornaram meretrizes e porque fizeram com que suas filhas adotivas seguissem os seus passos:

quia nos libertinae sumus, et ego et tua mater, ambae meretrices fuimus: illa té, ego hanc mihi educaui ex patribus conuenticiis. neque ego hanc superbiai caussa pepuli ad meretricium quaestum, nisi ut ne essurirem. (v.38-41)

Porque nós somos libertas, eu e a tua mãe nos tornamos ambas meretrizes: ela a ti, e eu a esta criei, porque vocês são de pais desconhecidos. Eu não levei esta para a profissão de cortesã por soberba mas sim para que não passasse fome.

Mas, parece não ser suficiente esta justificativa para a jovem. Ela então indaga à lena: At satius fuerat eam uiro dare nuptum potius. (v.43) (Ora essa! Mas teria sido melhor ter-lhe [Gimnásio] arranjado antes um marido.) E a mãe de Gimnasio então responde:

haec quidem ecastor cottidie uiro nubit, nupsitque hodie, nubet mox noctu: numquam ego hanc uiduam cubare siui.

nam si haec non nubat, lugubri fame familia pereat. (v.42-5)

Eh, Por Castor! De fato ela arranja marido todos os dias, a sério! Já teve um hoje, daqui a pouco, à noite, terá outro: eu nunca deixei que ela se deitasse viúva. Pois, se ela não tivesse marido, a família pereceria tristemente de fome.

Selênio é uma boa meretriz que realmente ama. Ela é, segundo Duncan, ${ }^{8}$ uma pseudo-hetaira que, ao fim da peça, será revelada como uma cidadã. Sobre a situação em que vive, Selênio diz à lena:

${ }^{8}$ Duncan, in Faraone e Macclure 1930, 259. 
(...) nam mea mater, quia ego nolo me meretricem dicier, opsecutast, gessit morem oranti morigerae mihi, ut me, quem ago amarem grauiter, sineret cum eo uiuere.

(...) É que minha mãe, como eu não quero tornar-me uma meretriz, fez-me a vontade e resolveu condescender com o que eu lhe suplicava, dando-me autorização para viver com o homem que eu amasse de verdade.

\section{Pelo que a lena lhe diz:}

stulte ecastor fecit. sed tu enumquam cum quiquam uiro consueuisti?

Por Castor, fez uma bobagem; mas tu acaso em algum tempo tivestes relações com algum homem?

\section{E a jovem responde}

nisi quidem cum Alcesimarcho, nemine, nec pudicitiam imminuit meam mihi quisquam alius. (v. 86-8)

Com ninguém, a não ser com Alcesimarco; e nenhum outro se aproveitou de mim.

Selênio expressa o seu amor e lealdade por Alcesimarco durante toda a peça e resiste aos conselhos da lena que afirma que ela deve ser mais mercenária. A lena diz à jovem:

matronae magi' conducibilest istuc, mea Selenium, unum amare et cum eo aetatem exigere quoi nuptast semel. (v.78-9)

É mais adequado a uma matrona, minha querida Selênio, essa questão de amar apenas um e com ele terminar a vida casada para sempre.

\section{E dá ao público uma interessante definição de meretriz:}

uerum enim meretrix fortunati est oppidi simillima: non potest suam rem optinere sola sine multis uiris. (v.80-1)

De fato realmente a meretriz é semelhante a uma cidade opulenta: não pode obter suas coisas sozinha, sem a ajuda de muitos homens.

\section{E ainda afirma:}

adsimulare amare oportet. nam si ames, extempulo melius illi multo, quem ames consulas quam rei tuae. (v.94-5)

É preciso fingir que se ama; pois se amas, te ocupas muito mais com aquele a quem amas do que com as tuas coisas. 
Percebemos que o ethos interesseiro da meretriz na peça não está expresso através do caráter de Selênio, mas sim nas falas e ações da lena e de sua filha Gimnásio. Diferentemente de Selênio, elas são maliciosas, espertas, mentirosas e interesseiras, e ao longo da peça afirmam que usam todos os seus estratagemas para extorquir dinheiro dos seus amantes através de seduções e enganos.

A comédia da cestinha, como uma típica comédia de reconhecimento, termina com uma cena de reconhecimento final, - Selênio descobre que é filha de pais livres - que possibilita a concretização do casamento dos jovens amantes.

\section{CONCLUSÃO}

Diante dessa breve análise, podemos concluir que a meretrix plautina pode ser representada com características predominantemente interesseiras ou apaixonadas. No primeiro caso, a meretriz não sofre durante toda a peça, arruína todos os seus amantes, e ao final, não há punição para essa personagem. No segundo caso, ela sofre ao longo da peça, por ser impedida de concretizar o seu amor, mas ao final, é recompensada com um reconhecimento, e o casamento com o jovem que ama. Dessa forma, podemos perceber que o fator principal que faz com que uma meretriz seja representada por Plauto como interesseira ou apaixonada é a condição social da jovem caracterizada: se ela é de nascimento livre, vai apresentar, predominantemente, características da meretriz apaixonada. Mas, se não há na peça nenhuma referência à sua origem, ou se ela é uma escrava, necessariamente, ela será uma meretriz interesseira.

Observamos que a verdadeira meretrix plautina possui um ethos interesseiro, semelhante à hetaira representada na comédia nova grega. A meretrix apaixonada, porém, não possui esse ethos, e, ainda que ocupe a posição de meretrix momentaneamente, está mais próxima da personagem da concubina na Comédia Nova grega, que tem relações somente com um homem, sem que o relacionamento tenha qualquer aspecto comercial. ${ }^{9}$ No último caso, as lenas são as personagens que se opõem a estas meretrizes, e que apresentam, através de suas falas, as características da "meretrix por excelência". 


\section{REFERÊNCIAS}

Cordeiro, Adriano M. 2010. Plauto: O Truculento. Intr. trad. e notas. Coimbra: Centro de Estudos Clássicos e Humanísticos.

Couto, Aires P. 2004. Plauto: A comédia da cestinha. Introdução e tradução. Coimbra: Festea.

Dupont, F. 1995. Teatro e societá a Roma. Trad. Giorgia Viano Marogna. Roma-Bari: Ed. Laterza.

Duckworth, G. E. 1994. The nature of roman comedy: a study in popular entertainment. University of Oklahoma Press: Norman.

Faraone, C. A.; Mcclure, L. K. 1930. Prostitutes \& Courtesans in the Ancient World. United States of America: University of Wisconsin System.

Grimal, P. 1978. O teatro antigo. São Paulo: Martins Fontes.

Hunter, R. L. 2009. A comédia nova da Grécia e de Roma. Trad. Rodrigo Tadeu Gonçalves (Cord. Trad.) Curitiba: Ed. Universidade Federal do Paraná.

Lindsay, W. M. 1989. Comoediae. Recognouit breuique adnotatione critica instruxit. t. I e II. New York: Oxonii Typographeo Clarendoniano.

Perna, Rafaelle 1954. La originalità di Plauto. Bari: Leonardo da Vinci.

Salles, C. 1982. Nos Submundos da Antigüidade. Trad. Carlos Nelson Coutinho. São Paulo: Brasiliense.

Spinelli, H. N. 2009. O Díscolo: estudo e tradução. Dissertação de Mestrado. Universidade de São Paulo. http://www.teses.usp.br/teses/disponiveis/8/8143/tde09122009-145805/ Acesso em 02/02/2012.

Title. Phronesium vs. Selenium: the plautine meretrix

Abstract. In this paper we analyze two of the main prostitutes of plautine plays, Phronesium, in Truculentus, and Selenium, in Cistellaria, in order to perceive how these personas are built by the author. We examine their discourse and also the voices of other personas that refer to them. The study is structured according to the concept of discursive ethos, developed by Dominique Maingueneau from the notion of rhetorical ethos.

Keywords. Plautus; meretrix; ethos. 